Revista LIDER, 37(22), 2020, pp. 9-24

eISSN: 0719-526

ISSN: 0717-0165

\title{
Reproducción distribuida: transformando representaciones de la desigualdad territorial ancladas en una matriz demográfico-espacial
}

\author{
Distributed reproduction: transforming \\ representations of territorial inequality anchored in a \\ demographic-spatial matrix
}

Juan Cristóbal Moreno Crossley
Universidad de Chile, Chile. jcristobalmoreno@gmail.com

RESUMEN

La investigación académica sobre desigualdad territorial frecuentemente asimila este concepto al examen de diferencias entre agregados humanos entendidos como poblaciones espacialmente separadas y delimitadas. Aun cuando esta mirada ha resultado prolífica en el sentido de evidenciar contrastes y denunciar la exclusión de individuos y colectivos humanos en el marco del modo de producción capitalista, supone una reducción de la propia noción de territorio, al que se asigna valor exclusivo como soporte para la existencia y reproducción de los seres humanos y donde el concepto de reproducción se vincula de manera estrecha al nacimiento y multiplicación de individuos como acto individual-corporal además de indicador de éxito y desarrollo social y económico. Recogiendo la crítica elaborada por Donna Haraway y Michelle Murphy al concepto de población como operador biopolítico, el presente artículo de investigación se propone reinscribir el estudio de las desigualdades territoriales en función de un concepto ampliado y distribuido de la reproducción, identificando su potencial para abordar la creciente polarización que caracteriza a la experiencia territorial contemporánea en América Latina.

Palabras clave: desigualdad; territorios; población; reproducción

ABSTRACT

Academic research on territorial inequality frequently assimilates this concept to the examination of differences between human aggregates understood as spatially separated and delimited populations. Even though this view has been prolific in the sense of highlighting contrasts and denouncing the exclusion of human individuals and collectives in the capitalist mode of production, it supposes a reduction of the very notion of territory. When territorial inequality is assimilated to population differences, territory then is viewed exclusively as a support for the existence and reproduction of human beings, closely linked to the birth and multiplication of individuals as an indicator of success and socioeconomic development. Based on the feminist critique made by Donna Haraway and Michelle Murphy of the concept of population as a biopolitical operator, this article seeks to reinscribe the study of territorial inequalities on an expanded and distributed concept of reproduction, and underlining its potential to address the growing polarization that characterizes contemporary territorial experience in Latin America.

Key words: inequality; territory; population; reproduction

Recibido: 13 de septiembre de 2020. Aceptado: 22 de noviembre de 2020.

DOI: $10.32735 /$ S0719-5265202037173 


\section{Introducción}

En su informe sobre "Desigualdad regional en Chile", elaborado el año 2018, el Programa de Naciones Unidas para el Desarrollo (PNUD, 2018) abordaba el análisis de un conjunto de brechas en materia de ingresos, salud y educación existentes entre las regiones del país con el propósito de relevar desafíos de política pública vinculados a la profundidad de las desigualdades existentes entre los territorios. En dicho informe, se establecía una definición de lo que se entendía por "desigualdades territoriales", señalando que éstas se referían a “(...) diferencias en dimensiones de la vida social que tienen una expresión territorial -esto es, que se muestran similares para los habitantes de un territorio y diferentes para otros-, que implican ventajas para los habitantes de unos territorios $y$ desventajas para los habitantes de otros, que se representan como condiciones estructurantes de la vida y que se perciben como injustas en sus orígenes o moralmente inaceptables en sus consecuencias" (PNUD, 2018, p. 5).

Tal como se desprende de este fragmento, a menudo, la discusión académica sobre desigualdades territoriales en Chile y América Latina envuelve un desplazamiento semántico, donde los territorios son concebidos preferentemente como receptáculos o contenedores de grupos humanos diferenciados en función de características susceptibles de ser ordenadas jerárquicamente en términos de capital, privilegio, estatus, bienestar, calidad de vida u otras variables. La distinción entre poblaciones circunscritas dentro de áreas o polígonos nítidamente delimitados (como es el caso de las unidades de la División Político Administrativa del país), mutuamente excluyentes entre sí y que contrastan por la magnitud o intensidad con que presentan ciertos atributos es, probablemente, la imagen o representación más recurrente en estudios que, mediante el examen de fenómenos contingentes tales como la segregación espacial residencial, la metropolización, la vulnerabilidad o la exclusión socioeconómica de grupos humanos en diferentes escalas, abordan la crítica de la desigualdad territorial.

La asociación de significados entre desigualdad territorial y desigualdad de poblaciones humanas espacialmente localizadas constituye, sin duda, una entrada sugerente y sumamente prolífica para evidenciar las contradicciones principales del modo de producción capitalista en su aguda expresión espacial y en referencia concreta a la experiencia de individuos y colectivos que resultan excluidos $\mathrm{u}$ oprimidos de conformidad con las relaciones sociales y económicas prevalecientes. Sin embargo, dicha asociación comporta, también, una reducción epistemológica, donde las complejidades del territorio y el control de sus riesgos se asimilan unívocamente a las condiciones para garantizar la existencia y reproducción sostenible de conjuntos de seres humanos definidos como poblaciones. 
Desde su crítica a la idea de biopoder, Michel Foucault señalaba ya a fines de la década de 1970, que el concepto de población desempeña un papel central en la transición desde una sociedad disciplinaria a una sociedad del control y la seguridad, representándose como sujeto colectivo de necesidades y de aspiraciones, pero también como fin e instrumento de gobierno (Foucault, 2008; Lemke, 2017). En este sentido, si el ejercicio del biopoder supone un conjunto de mecanismos normalizados de control que nacen conjuntamente con la modernidad (Foucault, 2014), el gobierno abandonará crecientemente un discurso político-militar asentado en la noción de poder soberano para abrazar un discurso racista-biológico, que comprende su finalidad y propósito explícito en términos de “(...) mejorar la suerte de las poblaciones, aumentar sus riquezas, la duración de la vida, su salud" (Foucault, 2008, p. 112). Y la población emerge, a su vez, como medio o instrumento de su propia gestión, donde a través de las estadísticas y de la definición de una normatividad implícita, permite distribuir el conjunto de lo viviente "en un dominio de valor y de utilidad" (Foucault, 2014, p. 174).

Donna Haraway (2018) radicaliza esta crítica apuntando a las bases del conocimiento científico moderno y denunciando cómo el uso de la población como un concepto pretendidamente neutro e inocente resulta antitético a la posibilidad de sustentar la vida y revertir el curso destructivo al que conduce el capitaloceno, entendido como "evento-límite" y amenaza de una ruptura irrecuperable de las relaciones entre las diferentes formas vivientes que existen sobre la tierra (Haraway, 2018; 2016). De acuerdo a esta autora, la población es una abstracción específica y situada, que transforma las vidas humanas y no humanas en cosas o cantidades masivas susceptibles de enumeración, desprovistas de subjetividad o cualidades, y despojadas de relaciones significativas con el resto de criaturas terrestres. El concepto de población, sin embargo, resulta tremendamente eficaz y se ha establecido como un lenguaje estandarizado y persuasivo que permite tanto a las ciencias sociales como a las ciencias de la naturaleza asignar valor a la vida, jerarquizar y determinar el destino de categorías enteras de seres humanos y no humanos sobre la base de su capacidad reproductiva (Haraway, 2018).

Por tal razón, Haraway plantea que tanto la población como la reproducción son operadores biopolíticos claves (Haraway, 2018), que producen ordenamientos y crean un mundo donde las múltiples formas de vida se asimilan a cosas o recursos cuya muerte o multiplicación constituye un indicador de su fortaleza y que desempeñan un rol específico en el marco de relaciones capitalistas de producción. Asimismo, la cosificación implicada en los conceptos de población y reproducción se construye sobre los cimientos de una epistemología individualista, hetero-patriarcal y centrada en el cuerpo, donde actos como la concepción, el nacimiento y la muerte se definen por referencia a decisiones racionales, autónomas e independientes. Tal 
como sugiere Michelle Murphy (2018), desde una perspectiva feminista se vuele necesario apuntar ya no solo al cuerpo y la reproducción como hechos individuales, sino pensar en el conjunto de condiciones que sostienen la vida colectiva y que hacen posible el nacimiento de seres vivos y sus relaciones. Ello implica reinscribir la noción de justicia reproductiva enarbolada por el movimiento feminista en un campo mucho más amplio de significado, donde la propia idea de reproducción implica dimensiones temporales y espaciales y se relaciona con múltiples infraestructuras y formas de vida.

A este concepto trascendente, intergeneracional y territorial, Murphy (2011) le denomina reproducción distribuida. Según se discutirá en el presente ensayo, la idea de reproducción distribuida reviste un significativo potencial para resignificar y reinterpretar las desigualdades territoriales fuera de un marco conceptual anclado en categorías de población. De allí, se desprende el objetivo de indagar sobre la pertinencia de un concepto ampliado y distribuido de reproducción -siguiendo las propuestas de Donna Haraway y Michelle Murphy- y evaluar su aplicabilidad para el estudio de la desigualdad territorial en el contexto latinoamericano.

En esta dirección, el presente ensayo considera tres apartados además de esta introducción. En el primero de ellos se ahonda en la crítica a los conceptos de población y reproducción considerando la visión de ambas autoras y explorando sus encadenamientos con la idea de justicia reproductiva, que juega un papel significativo tanto en la epistemología como en la praxis feminista. Luego, en el siguiente apartado se introduce la noción de reproducción distribuida elaborada por Murphy (2011), se examina su relación con otras epistemologías territoriales críticas y se aborda su proyección para el análisis de las realidades latinoamericanas con especial referencia al caso chileno. Finalmente, se exponen las conclusiones y se identifican algunos desafíos concretos para la investigación sobre las desigualdades territoriales sugiriendo caminos para superar miradas restringidas a una matriz demográfico-espacial.

\section{Crítica feminista a los conceptos de población y reproducción: Donna Haraway y Michelle Murphy}

En su producción académica reciente, Donna Haraway $(2018 ; 2016)$ ha acometido una crítica profunda a los soportes ontológicos y epistemológicos de nuestra época, resaltando cómo los procesos de deterioro de las condiciones de vida y destrucción de la naturaleza se encuentran íntimamente conectados con la desarticulación de las relaciones y ensamblajes existentes entre especies y cómo dicha desarticulación obedece a lógicas racistas, mercantiles y patriarcales. Estos procesos pueden ser resumidos por medio de diferentes denominaciones que 
enfatizan algunas de sus características o facetas más sobresalientes, incluyendo conceptos tales como el antropoceno (en tanto, primacía indiscutida de la especie humana sobre los ecosistemas terrestres), el capitaloceno (hegemonía del modo de producción capitalista y de sus relaciones como principio de organización de la naturaleza) y plantacioceno (reducción de la diversidad biológica a través de un intercambio genético desequilibrado e invasivo).

No obstante, más allá de sus particularidades, Haraway (2016) subraya cómo dichos procesos tensionan y amenazan la supervivencia de todos los seres vivientes, planteando la necesidad de pensar los tiempos en curso en términos de un "evento-límite" o un punto de inflexión, que puede gatillar una reversión y un cambio sustancial en la forma de comprender el rol de la humanidad en el planeta. Para ello, se vuelve relevante recuperar y revalorizar prácticas relacionales y cooperativas que están en los orígenes de la vida en la tierra y que señalan la posibilidad concreta de construir una relación de suma positiva y no de explotación entre las múltiples criaturas que la habitan y que, en sus palabras, incluye a humanos, más-que-humanos, otros-que-humanos, inhumanos y humanos "descompuestos" (humanos concebidos como humus o material de compostaje para el florecimiento de otras formas de vida). Dicho horizonte posible de recomposición o reconstitución de un "refugio" sólido de ensamblajes intra-activos y multi-especie decanta en el así denominado "cthulhuceno" (Haraway, 2016), como relato liberador de un mundo donde el auto-aprovechamiento y la depredación han sido sustituidos por una práctica sim-poiética, un hacer-con-otros y un convertirse-en-otros, y donde el individualismo y el auto-aseguramiento son reemplazados por una responshabilidad o capacidad respuesta colectiva y difusa (Haraway, 2018; 2016).

Encarando esta empresa, la autora extiende la crítica feminista a la idea de reproducción y justicia reproductiva, donde los humanos ya no solo deben adquirir la autonomía necesaria para tomar decisiones sobre su descendencia y ejercer el control activo de la natalidad, sino que deben reconocer el papel que les corresponde en un proyecto reproductivo ancestral, intergeneracional, multi-especie y de mucha mayor escala, que involucra la creación, reposición y transformación continua de la vida en la tierra. Según se expone en sus relatos (Haraway, 2018; 2016), la instrumentalización de la naturaleza y de la vida de las criaturas al servicio del dominio humano sobre el planeta ha conducido a una distorsión extrema, donde la vida y la muerte son fabricadas a escala industrial y sus consecuencias más evidentes se perciben en la incapacidad de sostener las condiciones indispensables para la supervivencia de la humanidad en el largo plazo. El nacimiento y la muerte como procesos naturales se transfiguran en el artificio de un "doble nacimiento" y de una "doble muerte", forzadas y producidas por colectivos humanos específicos para 
satisfacer intereses de supremacía biológica y expansión de su influencia sobre la faz de la tierra (Haraway, 2018).

Mientras la idea del "doble nacimiento" alude a la perversión o desviación del acto de creación de vida (reflejado en la explosión demográfica humana y en la presión por satisfacer sus necesidades alimentarias y de otro tipo mediante la producción ganadera a gran escala y el cultivo desmesurado de determinadas especies vegetales), la idea de la "doble muerte" señala la extinción o pérdida irreversible de formas vivientes que no prestan utilidad, no poseen valor económico o son "agotadas" en su carácter de recursos relevantes para sostener a las vidas que "sí importan" y no obstaculizar los procesos de acumulación de capital (poniendo de relieve procesos de exterminio de categorías enteras de vidas humanas y no humanas, ejemplificado en el genocidio de los pueblos originarios de América Latina o en la desaparición de numerosas especies animales y vegetales). El cénit de este proceso de fabricación masiva de vidas y desaparición selectiva de formas de vida se habría alcanzado, para Haraway, a contar de mediados del siglo XX, iniciando una etapa a la que denomina como la "gran aceleración", en que las poblaciones humanas aumentaron a un ritmo nunca antes visto, a la par del crecimiento de la industria de alimentos y la extinción de colectivos humanos y no humanos desprovistos de valor para consolidar el crecimiento económico continuo.

Dicha dinámica de aceleración se ve acompañada por la instalación de una episteme productivista y reproductivista y por el desarrollo consecutivo de tecnologías aplicadas a la gestión de poblaciones (humanas y no humanas). De allí se sigue la crítica que Haraway (2018) introduce al concepto de población, la que no está exenta de matices y limitaciones. Tal como reconoce la autora, la idea de población se encuentra omnipresente en el pensamiento y en la práctica científica, especialmente en el caso de las ciencias naturales, que han empleado este concepto como una herramienta abstracta y generalizada para la contabilidad, el análisis y la gestión. En su opinión, tanto las ciencias de la naturaleza como las ciencias de la riqueza (la economía, las finanzas y la administración) se gestaron "en los mismos tanques tóxicos" (Haraway, 2018), manifestando la necesidad de promover otras modalidades funcionales para la enumeración y el análisis de la información sobre el mundo natural.

Aunque se supone, en principio, como un concepto neutral y libre de connotaciones valóricas, la población-estrechamenteligada ala reproducción-emerge como "operador biopolítico clave", toda vez que traduce la pretensión de regular y fijar criterios funcionales a los intereses de determinados colectivos para decidir sobre la vida y la muerte. De tal suerte, en nombre de la población, se fomentará la natalidad y se estimularán condiciones para incrementar la reproducción de humanos, así como de plantas y de otros animales al servicio de la alimentación de unos y de otros, 
o bien se establecerán estrategias para el control reproductivo o la supresión de especies "invasoras", “dañinas", "débiles" o "improductivas".

Sin embargo, Haraway (2018) reconoce también el papel positivo que han desempeñado estudios que emplean el concepto de población como un instrumento para develar las desigualdades y desequilibrios generados por el capitalismo. En este sentido, destaca cómo la cuantificación y los análisis demográficos han puesto de relieve la magnitud de las inequidades a escala global, siendo ejercicios científicos de alto impacto, persuasivos y con innegable repercusión pública que han influido poderosamente en la promoción de transformaciones y detener los procesos de devastación que la propia perversión reproductiva ha intensificado sobre el planeta. Del mismo modo, también es consciente sobre la dificultad de desterrar el uso del concepto de población del lenguaje y la praxis científica, habida cuenta que, como mecanismo de contabilidad e instrumento analítico, forma parte del núcleo más elemental, incuestionado y transversal de la mayor parte de disciplinas científicas (Haraway, 2018). Sin perjuicio de lo anterior, Haraway ve necesario el desarrollo de alternativas, sugiriendo que los principales desafíos de las ciencias naturales no están en la enumeración deindividuos, sino en la observación de densidades y relaciones.

Son las densidades, los ensamblajes y los vínculos entre entidades, especies y categorías (y no las cantidades) las que habilitan una mayor libertad y otorgan derechos efectivos a los sujetos (humanos o no humanos) pensados siempre como personas. En base a esta reflexión, la autora convoca también a un desplazamiento de las políticas emancipatorias, entroncando el cuestionamiento a la población como categoría científica con la crítica feminista a la reproducción yalmodelohetero-patriarcal. Para posibilitar este encuentro, Haraway (2016) resignifica la noción de parentesco (kin) la que es planteada como una plataforma des-familiarizada y des-sanguinizada capaz de soportar relaciones múltiples, cooperativas y no competitivas entre las diferentes especies y criaturas terrestres. Reivindicando la proximidad etimológica entre kin (parentesco) y kind (gentil), la autora supone que la creación de parentesco puede ser desanclada de la reproducción biológica, abarcando las prácticas de cuidado, el refugio, la adopción, el apoyo mutuo y las relaciones horizontales, las relaciones entre "personas" que no necesariamente comparte una relación consanguínea o de nacimiento (Haraway, 2016). De tal forma, el parentesco puede ser pensado como una "composición" más que como un sistema de reglas de descendencia y regulación del patrimonio (Jáuregui, 1982; Levi-Strauss, 1998) y, por tanto, como un concepto social y naturalmente distribuido entre un variado conjunto de especies que cooperan y se ven comprometidas en su defensa y perduración. El parentesco y no la población, por tanto, puede sentar las bases para construir una capacidad de respuesta colectiva más allá de las fronteras presupuestas por los intereses de autoconservación, supremacía y multiplicación de una sola especie (Haraway, 2016). 
En congruencia con esta visión, Michelle Murphy (2018) subraya el papel jugado por la población en tanto concepto desarrollado en el siglo XX con el propósito de gobernar a las personas, tratadas como conjunto en pos del crecimiento económico perpetuo. Compartiendo la crítica de Haraway a la población como concepto genérico y abstracto y aparentemente despojado de carga valorativa y la intuición de Foucault respecto de su instalación como dispositivo biopolítico, Murphy (2018) detalla cómo la población reviste múltiples encarnaciones y aplicaciones, siendo tanto un artefacto de contabilidad como una fórmula que permite la anonimización de las vidas y su inscripción en conjuntos de datos intercambiables y eliminables. Asimismo, esta última autora describe la evolución sufrida por el concepto de población, remarcando cómo el uso deliberadamente eugenésico, racista y "preventivo" que tuvo en sus inicios se vio trastocado, desde la segunda mitad del siglo XX, en favor de la construcción de un aparato tecnológico comprehensivo, orientado a la gestión de colectivos humanos y no humanos de cara a los desafíos impuestos por la sobrepoblación y el aseguramiento del crecimiento económico (Murphy, 2018).

Aun cuando las tasas de natalidad humana han caído de manera significativa en la mayor parte del mundo desde fines del siglo XX, la gestión de poblaciones continúa siendo un objetivo central para la expansión del capital y encadena los procesos reproductivos con la planificación de inversiones. En estos términos, es que la noción de reproducción ya no podría ser pensada en referencia específica a decisiones o determinaciones individuales, sino que debe considerar el conjunto de condiciones e infraestructuras que hacen viable ciertas formas de vida y que, tal como sugiere Murphy (2018; 2011), remiten en su base a estructuras persistentes de carácter racista, colonial, heteropatriarcal y negadoras de otras posibilidades y relaciones. En esta dirección es que esta autora propone ampliar (y superar) el marco del pensamiento y la acción feministas sobre la justicia reproductiva para reinsertarlo en una lógica de justicia reproductiva distribuida y multi-especie, que se resume en su concepto de reproducción distribuida que se revisará y debatirá en la sección siguiente.

\section{El concepto de reproducción distribuida como clave para estudiar desigualdades territoriales}

Las concepciones usuales sobre la reproducción se centran en los cuerpos y en los individuos como unidad de referencia y foco de atención prioritaria. El comportamiento reproductivo de una población, por ejemplo, es medido en función del número de crías o descendientes que un individuo promedio, representativo de una especie, puede tener a lo largo de su vida. Desde esta perspectiva, además, 
reviste especial interés la consideración del número de individuos de sexo femenino, quienes, al reproducirse, hacen posible, por extensión, la reproducción de todo el colectivo del que forman parte. Esta visión forma parte del substrato común de los principales indicadores demográficos, siendo norma que la fecundidad (o número promedio de hijas e hijos que un individuo procrea durante su periodo fértil), en tanto principal indicador del comportamiento reproductivo de las poblaciones humanas, tome como referencia a las mujeres como unidad de análisis.

La Tasa Global de Fecundidad (TGF), por ejemplo, observa el número de hijos que una mujer tendría si estuviese sujeta a experimentar los patrones de descendencia en promedio observados en un año para todas las mujeres de un país o región determinado que se encuentran en edades fértiles (en el caso de Chile, se considera entre los 15 y 44 años de edad). Conforme a dicho indicador, se establece la noción de una fecundidad por encima o por debajo del "nivel de reemplazo", umbral definido por la cantidad de descendientes que son necesarios para reemplazar o sustituir a la población actualmente existente. Considerando que al menos se necesita que nazca una mujer para reemplazar a su madre y que, en promedio, nacen más hombres que mujeres, dicho umbral de reemplazo es convencionalmente fijado en un valor de 2,1 individuos nacidos vivos por mujer (Cabella y Nathan, 2018).

Como es supuesto, el nivel de reemplazo fija el imperativo de mantener un ritmo de nacimientos que consiga asegurar el crecimiento de las poblaciones sin poner en riesgo las bases de sustentación de una especie, para lo cual el crecimiento demográfico debe ir acompañado por un crecimiento económico de magnitud equivalente o superior. Pero, además, define explícitamente una responsabilidad que recae prioritariamente en las mujeres como sujeto del control reproductivo (Cabella y Nathan, 2018), por lo que tanto políticas pro-natalistas como políticas de planificación familiar identifican a las mujeres y a sus cuerpos como campo de disputa, bajo el supuesto. Según apunta Michelle Murphy (2018), esta atribución resulta congruente con un concepto tradicional y anclado en estructuras capitalistas, coloniales y hetero-patriarcales, que afirma que la reproducción como fenómeno de población inicia y concluye en los cuerpos, y que niega cualquier otra forma de responsabilidad ampliada más allá de las decisiones racionales de individuos aislados y genéricos.

Por otra parte, como sugiere Marji Gold (2019), el cuestionamiento al modelo de responsabilidad individual de la reproducción es un tópico de especial relevancia en la fundamentación del concepto de justicia reproductiva, que en décadas recientes se ha instalado como plataforma de lucha de las políticas feministas en superación al marco de los derechos sexuales y reproductivos. De acuerdo a la síntesis efectuada por esta autora, el concepto de justicia reproductiva involucra, a lo menos, cuatro 
principios básicos, a saber: (a) el derecho a no tener hijos/as (implicando la prevención del embarazo y el derecho al aborto seguro); (b) el derecho a tener hijos/as (asumiendo el ejercicio plenodelavoluntad en la decisión de tener hijos/as); (c) el derecho a criar hijos/as en entornos seguros y saludables (incluyendo un amplio espectro de condiciones a resguardar para el desarrollo de niñas y niños, tales como la protección del medio ambiente, el cambio climático, el sistema de justicia penal, garantías sobre el salario mínimo, condiciones decentes de trabajo, el derecho a la migración, la erradicación de todas las formas de violencia, y el derecho a la salud, entre otras); y, (d) la realización y el respeto pleno a la autonomía corporal personal.

La idea de una justicia reproductiva distribuida y multi-especie sugerida por Haraway y Murphy, por tanto, plantea una expansión de estos principios, arrancando de la constatación que la responsabilidad de la reproducción no es resorte de individuos y que la procreación y la crianza forman parte del trabajo ya no de una comunidad humana, sino del conjunto de seres vivientes y de sus relaciones con todos los elementos que condicionan la vida en la tierra, incluyendo el suelo, el agua, el aire, minerales, y donde el papel de las infraestructuras y productos generados por la acción humana tampoco resulta neutro. De esta forma, no solo se incorpora la crítica marxista a la idea de reproducción como un componente funcional al desarrollo capitalista, sino que se inscribe dicha crítica en una reconfiguración del papel de la humanidad como sujeto activo en el devenir de los procesos de devastación global que implica el antropoceno.

Como ha señalado Donna Haraway (2016), en el contexto del declive de las tasas de natalidad, el acto de tener bebés debiese ser un hito cada vez menos frecuente; un motivo de alegría a la vez que una responsabilidad que incumbe a una comunidad ampliada de personas -humanos y no humanos- que contribuyen a su crianza. Así, esta autora aboga por una política auténticamente feminista que considere la construcción de relaciones de parentesco ampliadas, donde se creen y mantengan lazos con "parientes extraños", improbables o distantes (oddkin) que están presentes en la naturaleza y que aseguren que la responsabilidad del cuidado sea efectivamente distribuida y garantizada (Haraway, 2016). En conformidad con lo anterior, la noción de justicia reproductiva se expresaría de múltiples formas, incluyendo, en un sentido más básico, que el acceso a medios de anticoncepción no necesiten ser impuestos por el imperativo del control de la población, pero también el despliegue de políticas genuinas de cuidado que incentiven la generación del parentesco no-natal, a través del refugio, la adopción, la acogida a inmigrantes, junto con una variedad de prácticas solidarias y la activación de un sentido de pertenencia comunitario (Haraway, 2018).

Michelle Murphy (2011) asimila dichas prácticas a la idea de reproducción distribuida, que busca reenfocar el contenido sustantivo del concepto de 
reproducción. Desde su mirada, la reproducción es un fenómeno que ocurre "más allá" de los cuerpos, y que opera dentro de infraestructuras temporales y espaciales atravesadas por desigualdades (Murphy, 2011). El cuerpo humano, entonces, no solo resulta estrecho en sus dimensiones como unidad de decisión de la reproducción, sino que su responsabilidad temporal se desancla de la duración de su vida individual. La sostenibilidad de la vida se juega en un tiempo que es intergeneracional, donde el conjunto de elementos que forman parte de la experiencia de las personas como sujetos territoriales resulta relevante y donde la interpenetración con los modos de producción dominantes es crucial.

En este sentido, es interesante resaltar la incorporación de una lectura que también es estructuralista en la propuesta de Murphy (2011), quien subraya como el discurrir de personas y colectivos es condicionado por matrices que fijan determinaciones a la vez que otorgan libertades y que son profundamente atravesadas por clivajes basados en el sexo, la raza y la clase social. De allí su convicción en torno al papel que desempeñan infraestructuras de influencia persistente en el tiempo, que hacen viable el despliegue de ciertos aspectos o facetas de la vida, mientras que niegan, sacrifican o abandonan otros. Del mismo modo, se abre la posibilidad de una convivencia potencialmente conflictiva de las diversas formas de vida frente a estructuras de carácter deliberadamenteracista, elitista o excluyente.

En la medida en que el pensamiento y la política reproductiva desbordan los cuerpos, la crítica feminista se intersecta con la economía política, poniendo de relieve el rol cumplido por diferentes sistemas funcionales y de producción del bienestar, incluyendo las políticas militares, la vivienda, el trabajo, la contaminación medioambiental, además de la influencia que en la actualidad revisten políticas biomédicas, tecnológicas y vinculadas al cambio climático, por solo mencionar algunas. Para Murphy (2011), la reproducción es simultáneamente dispersa, estratificada y distribuida, entretejiendo relaciones y expresándose en una doble configuración, que tiene componentes tanto de la biología como de la economía política. Adoptando, entonces, este punto de vista, el problema de la desigualdad territorial reclama una reformulación profunda, con el propósito de superar miradas que la abordan, superficialmente, desde su carácter de desigualdad de poblaciones humanas diferencialmente localizadas en el espacio.

Tal como se ilustró en la introducción, los enfoques convencionales para abordar la desigualdad territorial se amoldan a una matriz demográfico-espacial, donde el territorio es representado como un sistema categorial estable, que distingue y circunscribe a dichas poblaciones conforme a atributos que les confieren homogeneidad. Una forma paradigmática de producir esta matriz opera mediante la fijación de colectivos humanos según su residencia o domicilio, que permite diferenciar territorios favorecidos y desfavorecidos, "ganadores" o "perdedores". La 
Organización para la Cooperación y el Desarrollo (OCDE, 2020), por ejemplo, establece una tipología areal para examinar el bienestar en los territorios conforme a la identificación de poblaciones residentes en múltiples agregados territoriales, que incluyen a las regiones administrativas (grandes y pequeñas), a áreas urbanas funcionales (compuestas, a su vez, por unidades administrativas locales) y, en mayor grado de detalle, a celdas o cuadrículas de tamaño regular que suponen la unidad mínima de agregación de datos.

En América Latina, los enfoques seguidos por CEPAL (2016) son también tributarios de esta tradición, concibiendo al territorio como "eje estructurante" de la desigualdad social, y contrastando las condiciones de desarrollo existentes "entre territorios ricos y territorios pobres", en tanto determinantes del acceso a oportunidades y bienestar de las poblaciones que viven en ellos. Estas representaciones, a su vez, se trasladan al campo de la gestión territorial, por medio de diseños políticos y programáticos que abordan la situación de territorios "vulnerables", "rezagados" o "aislados", como entidades preferentemente receptoras de inversiones o subsidios.

En el caso de Chile, un ejemplo significativo lo constituye la recientemente implementada Política Nacional sobre Zonas Rezagadas, que apunta al objetivo de promover el "igual acceso de oportunidades entre las personas, independientemente del lugar donde habiten, focalizando recursos en aquellos territorios que presentan brechas de mayor magnitud en su desarrollo social" (Art. $1^{\circ}$ ) (Gobierno de Chile, 2018). A través de esta política, se insta a la definición de agrupaciones de comunas contiguas que presentan altos niveles de pobreza y aislamiento geográfico, y que, mediante el financiamiento preferente de proyectos de infraestructura y equipamiento comunitario y el trabajo coordinado entre órganos públicos y el sector privado podrían alcanzar "niveles de desarrollo no inferiores a su propia región" (Art. $1^{\circ}$ ) (Gobierno de Chile, 2018).

Entre las principales debilidades de estos enfoques se hace presente: (a) la asimilación de las cualidades de los territorios a las cualidades de la población (humana) que los ocupa; (b) la clausura operacional de los territorios para fines de descripción, análisis y gestión conforme a límites fijos y definidos; (c) la falta de atención a las relaciones y ensamblajes existentes entre entidades humanas y no humanas para la reproducción de la vida; y, (d) la disociación de los resultados observados en los colectivos humanos respecto del funcionamiento $y$ profundización de relaciones capitalistas de producción.

En el caso de América Latina, esta visión adquiere relevancia al observar que las consecuencias e impactos de las relaciones capitalistas de producción no solo envuelven el sufrimiento o degradación de las condiciones de vida de seres humanos, sino también la destrucción de ecosistemas completos. Dicha destrucción se 
manifiesta, entre otras dimensiones, en la devastación de los suelos, en la deforestación, la explotación de fuentes de agua y la pérdida de biodiversidad. La desigualdad territorial en la era del extractivismo y del neo-extractivismo requieren, por tanto, de un abordaje capaz de conectar los diferentes planos, ámbitos y dominios en los que las condiciones delavida de humanos y no humanos se ven amenazadas.

En convergencia con la visión de Saskia Sassen (2015), los procesos de acumulación en el capitalismo avanzado involucran extensivamente el procesamiento y transformación de un variado conjunto de elementos de la naturaleza tratados como commodities o materias primas, susceptibles de valorización económica, y cuyos subproductos y externalidades dan origen a territorios devastados. Lugares donde la tierra, el aire y el agua están "muertos" (Sassen, 2015), en el sentido de no ofrecer condiciones mínimas para la reproducción de la vida. Las poblaciones humanas, por tanto, no son la única "parte" del territorio que refleja estos impactos, sin pasar por alto el hecho que dichas poblaciones son, también móviles y que los daños materializados en los territorios se traducen asimismo en expulsiones masivas de población que busca refugio en las grandes ciudades. De tal suerte que los indicadores que describen a la población humana que "está" y permanece en los territorios pasan a ser tan relevantes como los indicadores que describen a la población expulsada o desaparecida de tales lugares. Asimismo, se percibe cómo la idea de población resulta fundamentalmente restrictiva, al no permitir capturar la especificidad de las identidades y elementos que están en juego.

Tal como ha sido indicado por Burchardt y Dietz (2014) los países latinoamericanos asisten a un proceso marcado simultáneamente por una reprimarización de sus economías, donde las actividades de extracción y exportación de materias primas se han vuelto a instalar como eje principal de acumulación de capital, de una parte, y por una creciente dependencia de las rentas generadas por la extracción de materias primas en el mejoramiento de las condiciones de vida de la población humana, de otra. En estecontexto, aun cuando el bienestar de las poblaciones y de sus principales indicadores socioeconómicos pudiese verse incrementado en el marco de ciclos en los que la demanda y la cotización de los commodities se eleva y sus excedentes permiten una redistribución al menos parcial de la renta, dichas mejorías se materializan a expensas del deterioro de la riqueza y diversidad biológica de sus territorios. De esta forma, el así llamado proyecto neo-extractivista, fundado sobre las bases de la apropiación privada y estatal de los procesos de extracción de materias primas, supone una relación antagónica con la naturaleza, donde los incrementos en el bienestar humano tienen como frontera la continuidad de los ciclos de reposición de la vida, tratada como stock de recursos cuyos derechos de acceso y explotación se ven crecientemente restringidos y monopolizados. 


\section{Conclusión}

El acercamiento a las realidades territoriales contemporáneas supone reconocer el conjunto de las condiciones que hacen posible la reproducción de la vida, incorporando en dicho diagnóstico no solo la evaluación de los efectos y resultados concretos de sus efectos sobre el bienestar de las poblaciones humanas, sino también sobre el conjunto de elementos de la naturaleza con los cuales se establecen ensamblajes ricos y creativos y de cuya salud depende también el bienestar humano y su sostenibilidad a mediano y largo plazo. En la medida que el concepto de población tiene preeminencia en el examen de las desigualdades territoriales, no solo se corre el riesgo de limitar u oscurecer los impactos que las relaciones capitalistas de producción tienen sobre los territorios, pues también implica una forma de contabilidad no neutral que desplaza el significado de dichos impactos, traduciendo a la naturaleza en recursos y a los seres humanos en activos susceptibles de ser gestionados eficientemente y valorizados para los procesos de acumulación de capital.

La crítica feminista a la noción de población, según se discutió, tiende puentes con la crítica postestructuralista a los dispositivos biopolíticos de saber-poder que emplean la medición estadística y la normativización demográfica como instrumentos de control y regulación. Pero, también, incorpora un reconocimiento abierto sobre el papel que juegan estructuras persistentes y opresoras fundadas sobre códigos de género, clase y raza que, en el contexto de la mirada histórica y comprehensiva que proponen las discusiones contemporáneas sobre el antropoceno y el capitaloceno, son reinscritas en un plano de significado más complejo y que involucra relaciones y una responsabilidad extendida hacia el cuidado de colectivos humanos y no humanos.

Por otra parte, se propone una transformación en la escala de referencia del proceso reproductivo. Siguiendo la progresión sugerida por Haraway (2018), adoptar un concepto de justicia reproductiva ampliado y multi-especie descorporaliza a la vez que desfamiliariza la idea de reproducción, con lo cual las luchas por la autonomía planteadas tradicionalmente por las feministas trascienden el ámbito de la libertad individual para ser redibujadas en términos que involucran una escala planetaria y un horizonte intergeneracional, además de un sentido fundamentalmente colectivo, tal como se refleja en su propuesta por una política de construcción de parentesco no-natal o no-consanguíneo.

Para América Latina, los desafíos implicados en la extensión del proyecto neoextractivista son de gran envergadura e implican tomar cuenta la fragilidad de los encadenamientos y relaciones existentes entre los componentes humanos y no humanos de la reproducción, que los procesos extractivos instalan en abierta oposición. Frente a estos desafíos, la idea de reproducción distribuida puede ser 
pensada como una herramienta práctica para la descripción de estas relaciones dinámicas e inciertas que tienen lugar en los territorios contemporáneos. Tal como señala Murphy (2018), al resignificar la reproducción como reproducción distribuida se abre también un espacio para imaginar la emergencia de otras vidas posibles o vidas alternativas (alterlife), donde el reconocimiento de la incertidumbre que pesa sobre el devenir de los territorios permite tomar consciencia sobre la responsabilidad y posibilidad de construir una relación distinta con otros humanos y no humanos.

En la medida que la reproducción se nutre de complejos entramados materiales con la tierra, el agua, elementos químicos, la atmósfera, ambientes naturales y construidos, su evolución es siempre incierta y sus resultados pueden ser alterados, sea de manera deseada o impuesta. La promesa de una recomposición de este tipo sigue teniendo sentido hoy para América Latina y está directamente relacionada con una reflexión sobre el conjunto de las condiciones amplias y distribuidas que se establecen para la reproducción de la vida en sus territorios.

\section{Bibliografía}

Burchardt, H. J., \& Dietz, K. (2014). (Neo-) extractivism-a new challenge for development theory from Latin America. Third World Quarterly, 35(3), 468486.

Cabella, W., \& Nathan, M. (2018). Los desafíos de la baja fecundidad en América Latina y el Caribe [Documento de trabajo]. Montevideo: Fondo de Población de las Naciones Unidas (UNFPA).

CEPAL (2016). La matriz de la desigualdad social en América Latina. Santiago de Chile: Comisión Económica para América Latina y el Caribe.

Foucault, M. (2014). Historia de la sexualidad/Vol. 1. La voluntad de saber (Vol. 1). México: Siglo XXI Editores.

Foucault, M. (2008). Seguridad, territorio, población (Vol. 265). Madrid: Ediciones AKAL.

Gobierno de Chile (2018). Aprueba reglamento que fija la política nacional sobre zonas rezagadas en materia social. Decreto $\mathrm{N}^{\circ} 975$ del 14.02.2019, Ministerio de Interior y Seguridad Pública.

Gold, M. (2019). De los derechos reproductivos a la justicia reproductiva/From Reproductive Rights to Reproductive Justice. Medicina Social, 12(2), 60-69.

Haraway, D. (2018). Making kin in the Chthulucene: reproducing multispecies justice. En Clarke, A. y Haraway, D. (2018). Making Kin Not Population, 6799. Chicago: Prickly Paradigm Press. 
Haraway, D. (2016). Staying with the trouble. Making kin in the Chthulucene. Durham: Duke University Press.

Jáuregui, J. (1982). Las relaciones de parentesco (1980). Nueva Antropología, (18), 179-208.

Lemke, T. (2017). Introducción a la biopolítica. México: Fondo de Cultura Económica.

Lévi-Strauss, C. (1998). Las estructuras fundamentales del parentesco. Barcelona: Editorial Paidós Ibérica.

Murphy, M. (2018). Against population, towards alterlife. En Clarke, A. y Haraway, D. (2018). Making Kin Not Population, 101-123. Chicago: Prickly Paradigm Press.

Murphy, M. (2011). Distributed reproduction. En Casper, M. y Currah, P. (2011). Corpus. An interdisciplinary reader on bodies and knowledge (pp. 21-38). New York: Palgrave Macmillan.

OCDE (2020), OECD Regions and cities at a glance 2020, OECD Publishing, Paris.

PNUD (2018). Desigualdad regional en Chile. Ingresos, salud y educación en perspectiva territorial. Santiago de Chile, Programa de las Naciones Unidas para el Desarrollo.

Sassen, S. (2015). Expulsiones: brutalidad y complejidad en la economía global (Vol. 3090). Madrid: Katz editores. 